* Mestre em Direito pela Universidade de Caxias do Sul (UCS)

E-mail: thiagogermano@yahoo. com.br

** Doutora em Direito pela Universidade de Santa Cruz do Sul (UNISC)

Professora em Direito na Universidade de Caxias do Sul (UCS) E-mail: ccalgaro1@ hotmail.com

*** Doutor em Direito pela Universidade do Vale do Rio dos Sinos (UNISINOS)

Professor em Ciência Jurídica na Universidade do Vale do Itajaí (UNIVALI) E-mail: litonlanes@ gmail.com

\section{A IMPORTÂNCIA DA SOLIDARIEDADE PARA IMPLEMENTAÇÃo DA JUSTIÇA E DA SUSTENTABILIDADE, NO DIREITO INTERNACIONAL AMBIENTAL, BASEADA NA TEORIA DA ECOLOGIA INTEGRAL}

\author{
THE IMPORTANCE OF SOLIDARITY FOR THE IMPLEMENTATION \\ OF JUSTICE AND SUSTAINABILITY, IN INTERNATIONAL \\ ENVIRONMENTAL LAW, BASED ON THE THEORY OF INTEGRAL \\ ECOLOGY
}

\section{Thiago Germano Álvares da Silva* Cleide Calgaro** Liton Lanes Pilau Sobrinho***}

Como citar: SILVA, Thiago Germano Álvares da; CALGARO, Cleide; PILAU SOBRINHO, Liton Lanes. A importância da solidariedade para implementação da justiça e da sustentabilidade, no Direito Internacional Ambiental, baseada na teoria da ecologia integral. Scientia Iuris, Londrina, v. 25, n. 2, p. 10-24, jul. 2021. DOI: $10.5433 / 21788189.2021 v 25 n 2 p 10$. ISSN: $2178-8189$.

Resumo:Opresentetrabalho analisa aimportânciada solidariedade na evolução do direito internacional ambiental. Objetiva-se, ao longo do estudo, proceder uma avaliação sobre em que medida o direito internacional ambiental foi se afastando de um de seus valores originais para a busca da justiça, analisando os percalços em implementar implicitamente ou explicitamente a solidariedade no sistema jurídico internacional. Também, discorre sobre desvirtuamentos e armadilhas que levam o direito internacional a se afastar dos valores solidários. Com isso, se deduz a necessidade de fortalecer marcos teóricos e doutrinas que aproximem o direito internacional ambiental dos seus valores originais e fundamentais, bem como a necessidade de retomar o foco dos acordos internacionais ambientais na justiça socioambiental, isto é, na busca por cooperação internacional para combater injustiças sociais e ambientais transnacionais. Não obstante, utiliza as diretrizes da ecologia integral e propostas de ação internacional contidas na Laudato Si', que valorizam a solidariedade em busca da justiça socioambiental. O método de estudo é analíticodedutivo. Nas considerações finais, se reconhece a importância da solidariedade para o direito internacional ambiental e a necessidade de se sanar as armadilhas e desvirtuamentos contidos no direito internacional em relação à solidariedade, necessário para a justiça e para a proteção ambiental, principais motivos para existirem acordos internacionais ambientais. 
Palavras-chave: direito internacional ambiental, solidariedade, ecologia integral, justiça, socioambientalismo.

Abstract: This paper analyzes the importance of solidarity in the evolution of international environmental law. The objective of this study is to evaluate the extent to which international environmental law has moved away from one of its original values in the search for justice, analyzing the obstacles to, implicitly or explicitly, develop solidarity in the international legal system. In addition, it discusses distortions and pitfalls that lead international law to distance itself from values of solidarity. With this, it is deduced the need to strengthen theoretical frameworks and doctrines that bring international environmental law closer to its original and fundamental values, as well as the need to return to the focus of international environmental agreements on social and environmental justice, that is, the search for international cooperation to combat transnational social and environmental injustices. Nonetheless, it uses the guidelines of integral ecology and proposals for international action contained in the Laudato $\mathrm{Si}$ ', which value solidarity in search of social and environmental justice. The method of study is analyticdeductive. The final considerations recognize the importance of solidarity for international environmental law and the need to remedy the pitfalls and distortions contained in international law in relation to solidarity, necessary for justice and environmental protection, the main reasons for the existence of international agreements environmental impacts.

Keywords: international environmental law, solidarity, integral ecology, justice, socio-environmentalism. 


\section{INTRODUÇÃO}

Entre os valores morais e princípios gerais do Direito na esfera ambiental, urge o princípio da solidariedade, sendo importantíssimo na evolução e nos interesses do direito internacional ambiental. Contudo, existe o esforço em identificá-lo no direito internacional ambiental, seja no sentido fraternal, cooperativo, nos direitos e nas responsabilidades, entre outros sentidos, pela busca final de justiça além das fronteiras.

O presente trabalho visa, inicialmente, analisar a importância da solidariedade na evolução do direito internacional ambiental. Após, discorre sobre algumas armadilhas contidas no direito internacional e desvirtuamentos dos valores solidários, ocasionado seja por pragmatismo dos acordos internacionais ou por desfaçatez dos agentes internacionais, prejudicando a busca internacional por justiça.

Para tentar evitar as armadilhas e desvirtuamentos que distanciam o direito internacional ambiental de seus objetivos, propõe-se utilizar como marco teórico a ecologia integral e as propostas de ação internacional contidas na "Carta Encíclica Laudato Si' do Santo Padre Francisco sobre o Cuidado da Casa Comum", que valoriza a solidariedade em busca da justiça socioambiental.

Para alcançar os objetivos propostos neste trabalho foi adotado método analítico-dedutivo, devido à natureza do estudo desenvolvido e ao procedimento de revisão da literatura, a partir de pesquisa bibliográfica e documental, essencialmente doutrinária, mas com eventuais aportes da jurisprudência e da legislação.

\section{O PRINCÍPIO DA SOLIDARIEDADE COMO UM PRINCÍPIO GERAL NO DIREITO INTERNACIONAL AMBIENTAL}

Princípios gerais têm sido frequentemente usados para preencher lacunas no direito internacional durante litígios entre Estados. Princípios gerais de direito são aqueles conceitos e regras encontrados nos principais sistemas legais do mundo e apropriados para aplicação nas relações internacionais. Uma vez que tais regras foram adotadas na legislação nacional, o consentimento para sua aplicação no direito internacional é inferido (KISS; SHELTON, 2007, p. 8).

As questões ambientais estão se caracterizando cada vez mais como um fator de divergências entre países em vários fóruns internacionais - e, de fato, o número de fóruns disponíveis para resolver conflitos ambientais está aumentando. O principal fórum internacional de resolução de conflitos ambientais é a Corte Internacional de Justiça (ICJ, International Court of Justice), principal órgão judicial das Nações Unidas, estabelecida em 1945, na continuação do seu antecessor, o Tribunal Permanente da Justiça Internacional (TPJI). O art. 38 do seu Estatuto fomentou e desenvolveu as principais bases do direito internacional, inicialmente redigido pela antecessora TPJI (SILVA, 2018, p.16-17).

Artigo 38: A Corte, cuja função é decidir de acordo com o direito internacional as 
controvérsias que lhe forem submetidas, aplicará:

a. as convenções internacionais, quer gerais, quer especiais, que estabeleçam regras expressamente reconhecidas pelos Estados litigantes;

b. o costume internacional, como prova de uma prática geral aceita como sendo o direito;

c. os princípios gerais de direito, reconhecidos pelas nações civilizadas;

d. sob ressalva da disposição do Artigo 59, as decisões judiciárias e a doutrina dos juristas mais qualificados das diferentes nações, como meio auxiliar para a determinação das regras de direito.

A presente disposição não prejudicará a faculdade da Corte de decidir uma questão ex aequo et bono, se as partes com isto concordarem (ESTATUTO... ${ }^{2019)}$

Apesar de se aplicar apenas ao ICJ, o art. 38 representa a lista oficial de bases normativas que os Estados identificaram e aceitaram como capazes de criar regras que os vinculassem, sendo a única listagem desse tipo. Estabelece, em ordem, convenções internacionais (tratados) gerais ou específicas, costumes internacionais como evidência de uma prática geral aceita como lei, e princípios gerais de direito reconhecidos pelas nações "civilizadas" (SILVA, 2018, p. 18).

Entre os princípios gerais do direito ambiental na esfera internacional, está o princípio da solidariedade, que provém da Revolução Francesa, por ser sinônimo de fraternidade (de acordo com Sarlet e Fensterseifer), para transformar-se em um marco jurídico dos direitos fundamentais de terceira geração (entre eles, o meio ambiente) e do Estado Socioambiental de Direito na contemporaneidade (SARLET; FENSTERSEIFER, 2014, p. 66). A solidariedade também provém do sentido clássico de “amizade política” em Aristóteles (DI LORENZO, 2010, p. 78).

O princípio da solidariedade é um princípio estrutural do direito internacional. No direito contemporâneo surgiu no século 19 elaborado cientificamente pelo sociólogo francês Émile Durkheim, sendo sua abordagem adotada por muitos, em particular pelo professor de direito Léon Duguit, um dos fundadores do direito público francês moderno, respondendo a dois importantes desafios de seu tempo: (1) que o direito público é legitimo quando é um serviço público e solidário; (2) dar uma alternativa, desenvolver um direito público mais democrático e liberal, baseando seus ensinamentos na solidariedade e no serviço público (BOGDANDY, 2010, p. 1-2).

É analisado primeiro como noção, depois como princípio político e finalmente como elemento jurídico do direito internacional, criando direitos e obrigações em conjunto (solidariedade positiva) ou respondendo aos perigos da ausência de solidariedade (solidariedade negativa) (WELLENS, 2010, p. 4).

São com estes sentidos que a Declaração Universal de Direitos Humanos estabelece em seu artigo $1^{\circ}$ que os seres humanos devem agir com espírito de fraternidade. Também, no artigo 26 instrui que a educação deve ser instituída com espírito de amizade entre os povos, em busca da paz. E no artigo 28 confere o direito de todos os indivíduos a fazerem parte de uma ordem social e internacional para efetuarem seus direitos e liberdades individuais e coletivas (ONU, 1948).

Em relação às políticas internacionais sobre meio ambiente, a solidariedade está inserida desde da primeira grande declaração das Nações Unidas sobre o Meio Ambiente, a Declaração 
de Estocolmo de 1972. Esta Declaração proclama sobre a importância de critérios e princípios em comum entre todos os povos para preservação do meio ambiente humano, ou seja, princípios solidários. Também, que todos participem equitativamente num esforço em comum, de cooperação internacional, colaborando entre si em prol do interesse de todos, o bem comum ambiental, para benefício do ser humano e de sua posteridade (solidariedade intergeracional) (ONU, 1972).

Em 1979, foi proposto que a teoria dos direitos humanos fosse denominada direitos de solidariedade, direitos de terceira geração. Para Karel Vasak os direitos de solidariedade expressam uma nova concepção de nacional e vida internacional da comunidade humana, entre estes "novos direitos", o direito ao meio ambiente (DRZEWICKI, 1984, p. 28).

Os dois elementos principais da noção de desenvolvimento sustentável no direito internacional ambiental - responsabilidades comuns, porém diferenciadas, e equidade intergeracional - têm sido ferramentas poderosas para o desenvolvimento e o esclarecimento do princípio da solidariedade. Podemos encontrar o mais alto grau de positivação do princípio da solidariedade nas disposições da Carta das Nações Unidas sobre a manutenção da paz e segurança internacional (WELLENS, 2010, p. 4).

A solidariedade é fundamento moral e de valor para a equidade no Direito. Equidade desempenha um papel importante na determinação da distribuição de direitos e responsabilidades em condições de escassez e desigualdade. Esta é a base do princípio da responsabilidade comum, porém diferenciada. O conceito internacional de preocupação comum não conota regras e obrigações específicas, mas estabelece a base legal geral para a comunidade em questão agir. Designar uma questão como uma preocupação comum, elimina o tópico da jurisdição interna exclusiva dos estados e torna isso um assunto legítimo para a regulamentação internacional, mesmo devendo equilibrar efeitos de leis com as soberanias nacionais (KISS; SHELTON, 2007, p. 104-114).

Mas é na Agenda 21, assinado na Rio 92 que a solidariedade adquire uma importância significativa para a cooperação internacional em busca de um bem comum. Enquanto a cooperação é uma ação em conjunto em busca de uma finalidade, solidariedade se apresenta no Direito como o reconhecimento da dignidade do outro, uma responsabilidade de todos por todos, uma ação concreta em favor do outro, enxergando o homem em sua integralidade enquanto pessoa humana (DI LORENZO, 2010, p. 18-19). A solidariedade imputa na cooperação outro patamar.

A solidariedade imposta pelos problemas globais exige uma evolução na cooperação entre os países industrializados e os países em desenvolvimento, envolvendo ajudar os países pobres a enfrentar o ônus da implementação de medidas ambientais, reconhecendo que a pobreza global é uma das principais causas da degradação ambiental. A solidariedade e as necessidades especiais refletem-se no princípio das responsabilidades comuns, mas diferenciadas. O resultado é uma ênfase crescente na parceria e na reciprocidade na proteção ambiental multilateral, bem como na inter-relação entre proteção ambiental e desenvolvimento (KISS; SHELTON, 2007, p. 41-42).

A partir da Rio 92, o princípio da solidariedade se consolidou em diversos acordos internacionais e como valor dos princípios equitativos, influenciando principalmente nos acordos 
das Conferências das Partes ${ }^{1}$. Como bases da Agenda 21, existem dois documentos: um deles é a Carta da Terra, que articula os princípios e políticas que devem guiar as partes internacionais para criar um mundo pacifico, solidário, justo, ambientalmente íntegro e saudável, enfim, um planeta onde todos os seres vivos, em qualquer época, tenham condição de viver com dignidade; o outro é a Declaração do Rio de Janeiro sobre Meio Ambiente e Desenvolvimento, assinada na Rio-92 por mais de 170 países. Essa declaração tem 27 princípios importantes para fomentar o desenvolvimento sustentável (diversos princípios almejam cooperação com viés solidário) (BORN, 2019).

A solidariedade faz parte da teoria pós-moderna de justiça, a justiça social. Mais moderna ainda é a justiça socioambiental, uma concepção de justiça que concilia liberdade individual, bemestar social e proteção do meio ambiente compartilhado pela sociedade.

Tradicionalmente no Direito, a solidariedade está associada à lei de obrigações, representando um princípio de responsabilidade mútua sobre a relação entre o indivíduo e a sociedade. A solidariedade é amplamente utilizada no direito ambiental, mas notoriamente difícil de definir no direito internacional ambiental. Num sentido mais amplo, a solidariedade descreve a relação ou a dinâmica dentro de uma comunidade e o compromisso de cooperação, apoio e (re)distribuição, de modo a responsabilizar os mais afortunados para com os membros menos afortunados da comunidade. Desta forma, a solidariedade pode ser vista como "o princípio de que a força de uma sociedade é medida no alcance em que os mais ricos responsabilizam-se pelos mais vulneráveis (WILLIAMS, 2019).

Esse princípio nos dá uma melhor compreensão do conteúdo e da estrutura de um regime específico. Como tal, é uma ferramenta para a interpretação. Também pode ser usado para preencher lacunas ou modificar inconsistências. Além disso, pode ser uma ferramenta para diferenciar mais adequadamente entre vários regimes legais e fazer uma avaliação dos novos regimes em desenvolvimento. Portanto, o princípio da solidariedade é um mecanismo que melhora a compreensão e desenvolvimento do direito internacional (WOLFRUM, 2010, p. 228).

Isso claramente reflete o problema das mudanças climáticas, por isso a solidariedade está inserida no princípio de responsabilidade comum, porém diferenciada no direito internacional ambiental. Assim, diante disso, o conceito de solidariedade apresenta um mecanismo potencial para a redistribuição de recursos e responsabilidades dentro da comunidade global (WILLIAMS, 2019).

Mas no âmbito internacional existem diversas armadilhas para implementação da solidariedade e o distanciamento de ações altruístas. Além dos inevitáveis desacordos entre Estados-Nações, há conflitos em relação ao nível apropriado de redistribuição (por exemplo, através da ajuda internacional ao desenvolvimento), ou em relação às emissões metas de redução (onde os estados continuam a debater as emissões apropriadas meta de redução para o benefício de todos) (WILLIAMS, 2019). Não obstante, debates sobre quem deve agir de forma altruísta e quem deve ser contemplado com uma ação solidária também prejudicam o debate político na

1 Conferências anuais criadas pela Convenção-Quadro sobre Mudanças Climáticas da ONU (UNFCCC), sendo a primeira conferência em 1995. 
esfera internacional.

Um exemplo é a China, que não é obrigada por acordos internacionais a diminuir suas emissões de carbono mesmo sendo responsável por mais de $30 \%$ das emissões de poluentes do planeta e sempre fazendo lobby nas Conferências das Partes para responsabilizar os países já desenvolvidos sem aceitar nenhuma responsabilização. Desde a criação da UNFCCC a China conseguiu impor nos acordos internacionais todos os seus interesses: como, na Rio92, sendo definido como um país em desenvolvimento, sem responsabilização equitativa de um país altamente poluidor; agiu no Protocolo de Kyoto como agente principal para fomentar as reduções de emissões dos 24 países mais desenvolvidos (em conluio com o G77); evita compromissos voluntários internacionais para a proteção ambiental, com receio de fragmentar o G77; em 1999, na COP-5 não aceitou discutir compromissos futuros; se tornou em 2006 o maior emissor de $\mathrm{CO} 2$ no mundo, mesmo participando de todas as negociações mundiais sobre mudanças climáticas (SILVA, 2018, p. 45). Um exemplo de país não-solidário.

Além de questões individuais dos agentes internacionais, há também o aspecto de uma desgovernança global sobre sustentabilidade, prejudicando os acordos multilaterais e gerando equívocos na própria interpretação de sustentabilidade, como no caso do desenvolvimento sustentável. O desenvolvimento sustentável é um conceito político, amplo para o progresso econômico e social, mas nada permite induzir que na sua origem (no Relatório Brundtland) tenha um conceito popularmente divulgado de ter apenas três dimensões - os "três pilares": econômico, social e ambiental -. Nas vezes que o relatório usa a expressão "dimensões", apresenta longas listas. Este conceito de três pilares é outra armadilha para implementar a solidariedade na esfera internacional, pois aparenta que, além de raso, o meio ambiente não passaria de um terço do desenvolvimento sustentável. O desenvolvimento e meio ambiente são "integrais e indivisíveis" (VEIGA, 2013, p. 109-110).

Infelizmente, na pauta global o conceito equivocado dos três pilares já foi inclusive ratificado em tratados internacionais, como a Declaração de Johanesburgo, em 2007, uma grande perda na prática internacional. Ademais, as leis internacionais de desenvolvimento sustentável devem adequar-se as diretrizes do $\mathrm{GATT}^{2} / \mathrm{OMC}$ e ao princípio 16 da Eco92, de que "não devem criar distorções significativas no comércio e investimento internacional". Isso demonstra que mesmo se necessário para a consolidação do desenvolvimento sustentável e para a ética na relação entre sociedade e meio ambiente, é ilegal pelas diretrizes econômicas distorcer o mercado em prol da justiça socioambiental. Trata-se de um paradoxo para o livre mercado e um contrasenso para os acordos internacionais. Se protege tecnologias de mercado ultrapassadas, bem como desrespeita-se a evolução dos interesses dos consumidores, prejudicando as novas tecnologias ofertadas e os novos interesses de procura do consumidor. No plano dos acordos internacionais, interfere drásticamente nos interesses verdadeiros dos acordos ambientais, tranformando em pétrea uma pauta que nem interesse é (distorcer ou não mercados), além de interferir na solidariedade e na autonomia da normatividade internacional ambiental (SILVA, 2018, p. 88-89).

O objetivo principal da sociedade internacional segundo Wellens é manter a paz e a segurança internacionais, eliminando os conflitos, travando os estados em uma base regulatória baseada no respeito recíproco e na não interferência mútua. É uma associação normativa à qual todos os estados pertencem e está institucionalizado na Carta da ONU. No entanto, o Memorando sobre Proteção de Pessoas em Caso de Desastres preparado pelo Secretariado da ONU observou-se sucintamente que $\square$ proteção é um conceito que assume diferentes significados em diferentes 2 Acordo Geral de Tarifas e Comércio. 
contextos, e não há definição apropriada para todas as situações $\square$. Por conseguinte, a responsabilidade de proteger assumirá diferentes formas e modos de aplicação em todo o ordenamento jurídico internacional: operará de maneira diferente em situações de violações graves dos direitos humanos comparado com os casos em que os Estados e a comunidade internacional estão enfrentando pandemias (WELLENS, 2010, p. 8, 11-12).

Mais controversas ainda são as tentativas de aplicar o conceito de patrimônio comum ao meio ambiente como um todo, porque seria manifestamente incompatível com o princípio da soberania e integridade territorial dos estados, apesar de não ser totalmente descartada e nem imoral (DRZEWICKI, 1984, p. 38).

Portanto, se pode e se deve procurar novos marcos teóricos e paradigmas para o direito internacional ambiental que sustentem a importância da empatia e da solidariedade no âmbito internacional, além de buscar fugir das armadilhas contratuais ou do utilitarismo do desenvolvimento sustentável como é implementado atualmente. Uma das propostas de justiça socioambiental baseadas na solidariedade é a teoria da ecologia integral.

Nos últimos anos, houve uma redescoberta dos fundamentos éticos e religiosos do direito internacional público. A solidariedade é, por causa de sua natureza, corretamente denominada "um princípio orientado por valores", com um forte fundamento ético. Não é diferente no direito internacional (WELLENS, 2010, p. 5), onde valores religiosos de solidariedade podem contribuir para o correto desenvolvimento das instituições internacionais.

No direito internacional sobre desastres, por exemplo, nos artigos 49 e 50 da Carta das Nações Unidas, a solidariedade é usada para ações em benefício de determinados estados, mas o processo de elaboração de direitos e obrigações relevantes já se arrasta há 25 anos. O princípio da solidariedade se torna operacional no caso de um Estado não conseguir enfrentar um desafio específico, trabalhando assim em conjunto com o princípio da subsidiariedade (WELLENS, 2010, p. 13).

\section{ECOLOGIA INTEGRAL: UMA PROPOSTA PARA A POLÍTICA INTERNACIONAL}

Buscando novos marcos teóricos que privilegiem a solidariedade com intuito de buscar justiça socioambiental (para superar o "utilitarismo verde" e armadilhas dos acordos internacionais), se faz necessário a análise da proposta socioambiental contida na "Encíclica Laudato Si' do Santo Padre Francisco sobre o Cuidado da Casa Comum".

\subsection{ECOLOGIA INTEGRAL}

A solidariedade, como princípio do direito internacional, cria um contexto para cooperação que vai além do conceito de um estado de bem-estar global; na legislação reflete e reforça a ideia mais ampla de uma comunidade mundial de estados interdependentes. Embora difícil de ser aplicada e com conceito amplo, a solidariedade implica uma obrigação legal adicional para os Estados-nações para ajudar países menos desenvolvidos, ou no mínimo, não interferir com interesses de outros Estados (WILLIAMS, 2019).

Se trata também de um ethos. Um elemento ético na relação internacional. Por isso, vem com importância e complementação apropriada à solidariedade o conceito ético de ecologia integral proposto na Encíclica Laudato Si’ do Papa Francisco sobre o cuidado com a Casa Comum 
(FRANCISCO, 2015, §59).

Nesta "Encíclica Laudato Si' se apresentam diversos questionamentos sobre a crise que ocorre em nosso planeta, a casa comum. Entre estes questionamentos, estão a preocupação com a crise ambiental e a degradação humana e alerta sobre a falta de instrumentos de controle para a dívida ecológica dos países ricos, concluindo que se faz necessário que os países desenvolvidos contribuam (solidariamente) para resolver essa dívida, limitando significativamente o consumo de energia não renovável e fornecendo recursos aos países mais necessitados para promover políticas e programas de desenvolvimento sustentável (SILVA, 2018, p. 80).

Depois de diversas críticas analíticas sobre a crise socioambiental, a Laudato Si’ se atém a propostas para combater os problemas, como a ecologia integral, uma proposta antropológica que tenta se desgarrar do antropocentrismo. Baseia-se no humanismo integral proposto por Jacques Maritain, mas também tem base biocêntrica e teleológica, porque não existe crise ambiental, mas crise socioambiental, de forma integral e indivisível.

Diferente do desenvolvimento sustentável, a ecologia integral não tem origem em um conceito político, muito menos a obrigatoriedade de não distorcer mercados. Trata-se de um constante desenvolvimento da justiça social oriundo da tradição aristotélica-tomista ${ }^{3}$.

A justiça socioambiental só tem a fortalecer suas bases quando complementada com a escolástica, realizando de maneira equitativa as necessidades relativas ao desenvolvimento sustentável e ao meio ambiente das futuras gerações, exprimindo Justiça Social (KISS, 2005, p. 48). Não se trata de fomentar desenvolvimento ou proteger a natureza, mas propagar justiça.

Ou seja, a "pegada solidária", a preocupação em erradicar pobreza e concomitantemente buscar a forma correta dos indivíduos de se relacionarem com o meio ambiente que compartilham é mais nítido e não, necessariamente, abre concessões para o desenvolvimento e valores econômicos, sendo inseridos de forma a satisfazer a justiça social e a proteção ambiental, além de não necessitar instrumentalizar o viés econômico como um pilar igualmente reconhecido como tão importante quanto o socioambiental na estrutura conceitual-ideológica, como no caso do desenvolvimento sustentável (SILVA. 2018, p. 90).

Enquanto o desenvolvimento sustentável não pode distorcer o mercado, a ecologia integral pode "flexibilizar" inclusive a proteção ambiental: basta a degradação ser feita por uma pessoa explorada ou excluída. Neste caso, o antiético não é a relação do explorado em degradar o ambiente, mas sim, o antiético é o aspecto triangular existente entre uma pessoa exploradora ou incluída sendo indiferente (sem empatia e não-solidária) com a exclusão e exploração de outro, consequentemente gerando degradação ambiental.

A base socioambiental e ética da ecologia integral é a relação do indivíduo com outro indivíduo e de ambos no cuidado da casa comum. Se dá com a não indiferença ao outro e da relação destes com o cosmos, com o ambiente em que habitam. Com esta base teórica é que se organizam os "pilares" propostos na ecologia integral. Por isso, a erradicação da pobreza extrema

3 Aristóteles e São Tomás de Aquino. 
e da exploração humana tornam-se fundamentos na proteção ambiental e não meramente objetivos (SILVA. 2018, p. 90-91). Tem a ideia de que o explorado não tem margem de ação para proteger a natureza, convergindo com ideais de origem dos primeiros acordos internacionais ambientais e da justiça socioambiental.

Figura 1 - Teorema da ecologia integral

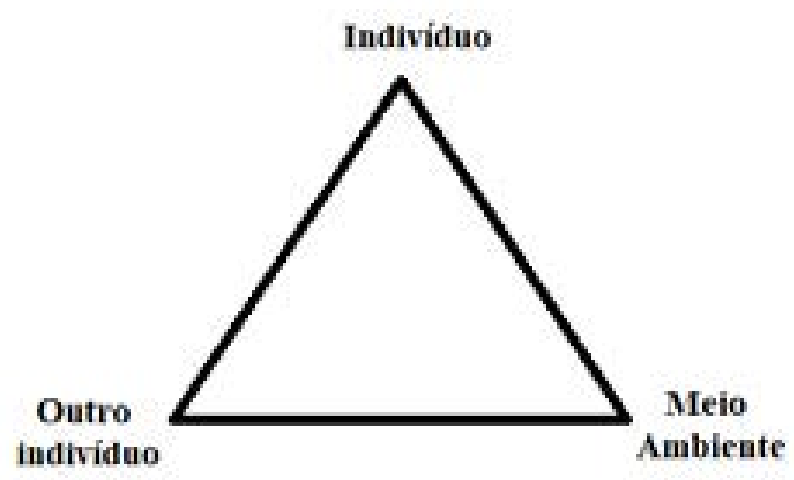

Fonte: Silva (2018, p. 91).

Deste modo, na tabela acima (meramente ilustrativa) a ecologia integral visa uma visão sistêmica, onde a solidariedade é uma premente preocupação humana, como uma preocupação ambiental visando assim um enfrentamento dos problemas advindos da política internacional e a busca de uma justiça socioambiental.

\subsection{A Solidariedade na Proposta para a Política Internacional}

Baseado na proposta de amor civil e político (origem gregas da solidariedade), a Laudato Si' prega fraternidade universal, em prol do bem comum e libertando-se da indiferença consumista (FRANCISCO, 2015, §228-232).

Em suas linhas de orientação e ação, propõe um diálogo sobre o meio ambiente na política internacional, com a ideia do planeta como pátria e a humanidade como povo que habita uma casa comum, concluindo que somos interdependentes, obrigados a pensar num mundo e num projeto em comum (SILVA, 2018, p.92).

Vai ao encontro da solução da pergunta "A quem a solidariedade é devida: ao outro Estado, a outra população, ou à comunidade, ou a indivíduos?” A responsabilidade de proteger mostra interação com o princípio da solidariedade. Existe a obrigação ou a responsabilidade pela assistência como um sistema baseado em valores e que existem direitos e obrigações mútuos (WOLFRUM, 2010, p. 227). Caso esses ideais entrem em vigor, teremos uma mudança na percepção do direito internacional. De repente, não teríamos apenas a obrigação ou a responsabilidade de um Estado de aderir aos direitos humanos em relação aos seus próprios cidadãos em seu território, mas iríamos além disso. Como no direito ambiental, a equidade intergeracional entrou em questão (WOLFRUM, 2010, p. 227).

Entre as diretrizes desta proposta estão a ineficácia dos acordos internacionais 
socioambientais para a obtenção da justiça, não podendo tais negociações internacionais avançar significativamente por causa das posições dos países que privilegiam seus interesses nacionais sobre o bem comum global (FRANCISCO, 2015, §169). É uma crítica a postura não solidária e fraternal.

Afirma que deve se valorizar subsídios para energia solar, bem como acordos internacionais com eficácia de interferência, para que estes se cumpram (FRANCISCO, 2015, $\S 173)$. Fica explícito que a Laudato Si' está demonstrando a preocupação do Papa Francisco com as leis internacionais "soft law" que não produzem ipso jure (força de lei), ou não tem efeito de responsabilidades e obrigações, sejam por forças, internacional ou nacional, incapazes de cumprirem os acordos ou regramentos institucionais (SILVA, 2018, p. 92-93).

Outro ponto de crítica e de proposta é sobre a tecnologia baseada nos combustíveis fósseis, altamente poluente, devendo ser progressivamente substituído. Contudo, afirma-se na Encíclica que apostar na internacionalização dos custos ambientais tem o perigo de impor aos países pobres compromissos de redução de emissões comparáveis aos dos países mais industrializados, fugindo da justa responsabilidade. Os países que foram beneficiados por um alto grau de industrialização à custa de uma enorme emissão de efeito estufa, têm maior responsabilidade em contribuir para a solução dos problemas que causaram (SILVA, 2018, p. 93).

Também, o Papa Francisco afirma que o mercado de crédito de carbono pode levar a uma nova forma de especulação, que não ajudaria a reduzir a emissão global de gases poluentes, podendo tornar-se um método que permite sustentar o consumo excessivo de alguns países e setores (FRANCISCO, 2015,§171).

Na Encíclica, afirma-se que a prioridade dos países em desenvolvimento é a erradicação da miséria. É preciso para salvaguardar o meio ambiente o desarmamento, a segurança alimentar e paz. Também, propõe acordo sobre governança dos recursos marinhos, prevenção em relação aos países atingidos pela crise socioambiental de agravamentos climáticos e da desigualdade, salvaguardando o ambiente, regulando fluxos migratórios, com autoridade política mundial promovendo estratégias internacionais (SILVA, 2018, p. 94). Mais uma vez, a preocupação é com fatores de empatia global que levam a solidariedade e fraternidade entre os povos, com o intuito final de justiça socioambiental.

Se houver uma obrigação moral de mitigar a mudança climática, e ajudar os pobres, então, por extensão, há uma obrigação moral de escolher estratégias eficazes para alcançar ambos os objetivos. Os críticos temem que os mecanismos de mercado possam oferecer uma fuga de tais obrigações que transferem os encargos dos ricos para os pobres (MONAST, MURRAY; WIENER, 2017, p. 153).

A tarefa da ecologia integral e da sustentabilidade socioambiental tem em seus aspectos estruturais a passagem para métodos sustentáveis da economia, não bastando apenas uma conduta conforme o mercado, mas sim ser mudadas as condições básicas da economia de mercado. A modificação dessas condições básicas é uma tarefa coletiva, devendo ser consideradas as partes 
ricas e partes pobres da população mundial (SILVA, 2018, p. 103).

É neste interim, que a ecologia integral retoma os anseios originais dos acordos internacionais ambientais, em busca da preservação ambiental calcada na justiça socioambiental, com solidariedade presente e intergeracional.

A sua efetivação à jurisdição internacional ambiental deve se basear em decisões políticas, atentando um procedimento que assegure a atuação da coletividade, levando assim a uma necessária jurisdição não apenas ambiental, mas em todo o direito internacional (SILVA; CALGARO; SOUZA, 2020, p. 438).

\section{CONSIDERAÇÕES FINAIS}

Basicamente, a solidariedade produz três dimensões no direito internacional: solidariedade entre Estados-Nações, solidariedade entre Estados-Nação e indivíduos e solidariedade intergeracional, perante as futuras gerações. No entanto, o conhecimento sobre a importância da solidariedade nos valores, princípios e regras internacionais ambientais é incompleta no direito internacional ambiental e precisa ser desenvolvida. A solidariedade é desenvolvida de forma diferente nas áreas do direito. É mais avançado no direito socioeconômico, mas subdesenvolvidos em outras áreas jurídicas como a socioambiental, que abrangem preocupações com desastres ambientais e solidariedade com as futuras gerações. (DOMURATH, 2013, p. 460). A solidariedade transnacional, entre Estados-Nações, na maioria das vezes é conferido seu caráter jurídico como cooperação.

A solidariedade faz parte dos valores, da moralidade e dos princípios gerais do direito internacional ambiental. Está embutido na motivação de existirem acordos internacionais ambientais. Faz parte de toda evolução jurídica dos acordos internacionais a necessidade de empatia, com objetivo de uma ação solidária em busca da justiça e do bem comum.

Porém, os valores e moralidades originais contidos na justiça socioambiental por vezes vão perdendo força diante do pragmatismo de um direito positivado e acordado em relações bilaterais ou multilaterais, como no direito internacional. Muitas vezes, estes acordos internacionais desvirtuam os sentidos de proteção ambiental e solidariedade social que são a base dos acordos ambientais, como no caso da obrigação de não distorcer mercados, o papel internacional da China ou os erros de interpretação do que é desenvolvimento sustentável.

Todo o ordenamento jurídico ambiental internacional depende da vontade das partes, os Estados-Nações. Não basear-se na solidariedade significa não fazer justiça nas questões ambientais transnacionais. O direito internacional não deve se distanciar de uma de suas diretrizes mais redigidas em textos: a cooperação com valor solidário. Para isso, fundamental a empatia, capacidade de cognição e emoção diante do outro, que muitas vezes não se encontra tipificado como parte nos acordos ou responsabilidades internacionais.

Por isso, é de suma importância retomarmos doutrinariamente aos anseios originais do direito ambiental e fortalecê-los, utilizando por base marcos teóricos que ainda estejam enraizados na justiça socioambiental, baseadas na empatia e consequentemente na solidariedade. Entre esses 
marcos teóricos, a Laudato Si' se destaca com essa visão de integralidade entre crises ambientais e humanas, com um olhar de justiça de forma hermenêutica. Nem sempre o aspecto antiético se dá na degradação ambiental, mas sim se dá na degradação das relações sociais, que geram o dano ambiental; e, nem sempre o desenvolvimento econômico deve ser protegido, mas sim os interesses socioambientais.

A Encíclica traz o cuidado com a casa comum, visto que existe uma conexão sistêmica entre o ser humano e a natureza, a qual precisa ser respeitada e harmonizada. Também existe a necessidade de se minimizar as injustiças entre os seres humanos, onde "poucos possuem muito e muitos possuem pouco", a alteridade e a solidariedade são dois vetores que precisam ser implementados pelos povos. Outros fatores como a empatia e a cooperação são fundamentais para a convivência e o respeito entre os seres humanos, contudo há necessidade do reconhecimento desses fundamentos pela comunidade internacional.

Não há como falar em superação de injustiças se não houver solidariedade entre os povos, reconhecimento do outro no direito internacional. O esforço de reconhecer o outro obscuro em muitos acordos é ao mesmo tempo identificar as vítimas e fomentar a justiça em todo o mundo.

O fim da solidariedade no direito é o fim da democracia e da justiça, pois apenas num ambiente democrático os indivíduos ou grupos conseguem acessar ao judiciário com suas devidas personalidades jurídicas a fim de se fazer cumprir seus direitos, sejam na esfera nacional ou na esfera internacional.

A ecologia integral permite que os anseios originais dos acordos internacionais ambientais, busquem uma preservação ambiental que seja efetivada em uma justiça socioambiental, com bases na solidariedade e na intergeracionalidade. Deste modo, é preciso perceber que tudo está interconectado e interligado para que exista a construção da casa comum, com a proteção dos ciclos vitais da natureza e dos direitos fundamentais dos povos que precisam de justiça social.

O paradigma da ecologia integral se dá pelas dinâmicas sociais e institucionais em todos os níveis, por isso o Papa denota que "se tudo está em relação, também o estado de saúde das instituições de uma sociedade comporta consequências para o ambiente e para a qualidade da vida humana [...]". Por isso, "a ecologia social é necessariamente institucional e atinge progressivamente diversas dimensões que vão do grupo social primário, a família, até a vida internacional, passando pela comunidade local e a Nação" (FRANCISCO, §142, 2015).

É importante que os países busquem uma visão integral para o bem-estar da sociedade e, principalmente, dos ciclos vitais da natureza. A sustentabilidade em seus tripés econômico, social e ambiental deve ser efetivada por todos. Como afirma o Papa "todos nós, seres humanos, caminhamos juntos como irmãos e irmãs numa peregrinação maravilhosa, entrelaçados pelo amor que Deus tem a cada uma das suas criaturas e que nos une também, com terna afeição, ao irmão sol, à irmã lua, ao irmão rio e à mãe Terra" (FRANCISCO, § 92, 2015). Portanto, a ecologia integral busca uma visão sistêmica, sendo que a solidariedade vem a ser uma preocupação humana, mas também existe a necessidade de uma preocupação ambiental, pois com isso tem-se a viabilidade de enfrentamento dos problemas advindos da política internacional e a busca de uma justiça 
socioambiental.

\section{REFERÊNCIAS}

BOGDANDY, Armin Von. Opening address. In: WOLFRUM, Rüdiger; KOJIMA, Chie (orgs.). Solidarity: a structural principle of international law. Springer: New York, 2010.

BORN, Rubens Harry. Agenda 21 e sustentabilidade. In: BRASIL. Ministério do Meio Ambiente. Comissão de políticas de desenvolvimento sustentável e Agenda 21 brasileira. Brasília: MMA, Disponível em: http://www.mma.gov.br/estruturas/agenda21/_arquivos/ CadernodeDebates9.pdf. Acesso em: 13 mar. 2019.

ONU - ORGANIZAÇÃO DAS NAÇÕES UNIDAS. Declaração de Estocolmo sobre o ambiente humano - 1972. São Paulo: Comissão dos Direitos Humanos, 1972. Disponível em: http://www.direitoshumanos.usp.br/index.php/Meio-Ambiente/declaracao-de-estocolmo-sobre-oambiente-humano.html. Acesso em: 13 mar. 2019.

ONU - ORGANIZAÇÃO DAS NAÇÕES UNIDAS - BRASIL. Declaração Universal dos Direitos Humanos. Brasília: ONU Brasil, 1948. Disponível em: https://brasil.un.org/ptbr/66717-declaracao-universal-dos-direitos-humanos. Acesso em: 20 fev. 2019.

DI LORENZO, Wambert Gomes. Teoria do estado de solidariedade: da dignidade da pessoa aos seus princípios corolários. Rio de Janeiro: Elsevier, 2010.

DRZEWICKI, Krzysztof. The rights of solidarity- the third revolution of human rights. Nordic Journal of International Law, Leiden, v. 53, n. 1, p. 26-46, jan. 1984.

DOMURATH, Irina. The three dhimensions of solidarity in the EU legal order: dimits of the judicial and legal approach. Journal of European Integration, London, v. 35, n. 4, p. 459-475, aug. 2013. Disponível em: https://www.tandfonline.com/doi/ pdf/10.1080/07036337.2012.704630?needAccess=true. Acesso em: 20 fev. 2019.

BRASIL. Decreto $\mathbf{n}^{0}$ 19.841, de 22 de outubro de 1945. Promulga a Carta das Nações Unidas, da qual faz parte integrante o anexo Estatuto da Corte Internacional de Justiça, assinada em São Francisco, a 26 de junho de 1945, por ocasião da Conferência de Organização Internacional das Nações Unidas. Brasília: Presidência da República, 1945. Disponível em: http://www.planalto. gov.br/ccivil_03/decreto/1930-1949/d19841.htm. Acesso em: 13 mar. 2019.

FRANCISCO, Padre. Carta Encíclica Laudato Si' do Santo Papa Francisco sobre o Cuidado da Casa Comum. Roma: Vaticano, 2015. Disponível em: http://w2.vatican.va/content/francesco/ pt/encyclicals/documents/papa-francesco_20150524_enciclica-laudato-si.html. Acesso em: 21 fev. 2019.

KISS, Alexandre. Justiça ambiental e religiões cristãs. In: KISHI, Sandra Akemi Shimada; SILVA, Solange Teles da; SOARES, Inês Virgínia Prado. (org.). Desafios do direito ambiental no século XXI: estudos em homenagem a Paulo Afonso Leme Machado. São Paulo: Malheiros, 2005. 
KISS, Alexandre; SHELTON, Dinah. Guide to international environmental law. Leiden: Koninklijke Brill NV, 2007.

MONAST, Jonas J.; MURRAY, Brian C.; WIENER, Jonathan B. On morals, markets and climate change: exploring on Pope Francis Challenge. Law and Contemporary Problems, Durham, v. 80, n. 1, p. 135-162, 2017. Disponível em: https://scholarship.law.duke.edu/cgi/viewcontent. cgi? article=4818\&context=lcp. Acesso em: 21 fev. 2019 .

SARLET, Ingo Wolfgang; FENSTERSEIFER, Tiago. Princípios do direito ambiental. São Paulo: Saraiva, 2014.

SILVA, Thiago Germano Álvares da. O mercado de crédito de carbono na política internacional e a preservação socioambiental para a viabilidade de uma ecologia integral. 2018. 118 f. Dissertação (Mestrado em Direito Ambiental e Novos Direitos) - Universidade de Caxias do Sul, Caxias do Sul, 2018.

SILVA, Thiago Germano Álvares da; CALGARO, Cleide; SOUZA, Leonardo da Rocha. A importância da empatia e da solidariedade para as tutelas coletivas decorrentes do direito internacional ambiental. Revista Direitos Sociais e Políticas Públicas, Bebedouro, v. 8, n. 1, p.429-457, jan./abr. 2020. Disponível em: https://www.unifafibe.com.br/revista/index.php/ direitos-sociais-politicas-pub/article/view/763. Acesso em: Acesso em: 21 fev. 2019.

VEIGA, José Eli da. A desgovernança mundial da sustentabilidade. São Paulo: Editora 34, 2013.

WELLENS, Karel. Revisiting solidarity as a (Re-) emerging constitutional principle: some further reflections. In: WOLFRUM, Rüdiger; KOJIMA, Chie (org.). Solidarity: a structural principle of international law. Nova York: Springer, 2010.

WILLIAMS, Angela. Solidarity, justice and climate change law. Melbourne Journal of International Law, Victoria, v.10, n. 2, oct. 2009. Disponível em: https://law.unimelb.edu.au/ data/assets/pdf_file/0004/1686190/Williams.pdf. Acesso em: 13 mar. 2019.

WOLFRUM, Rüdiger. Concluding remarks. In: WOLFRUM, Rüdiger; KOJIMA, Chie (Org.). Solidarity: a structural principle of international law. Nova York: Springer, 2010.

Como citar: SILVA, Thiago Germano Álvares da; CALGARO, Cleide; PILAU SOBRINHO, Liton Lanes. A importância da solidariedade para implementação da justiça e da sustentabilidade, no Direito Internacional Ambiental, baseada na teoria da ecologia integral. Scientia Iuris, Londrina, v. 25, n. 2, p. 10-24, jul. 2021. DOI: 10.5433/21788189.2021v25n2p10. ISSN: 2178-8189.

Recebido em 05/22/2020

Aprovado em 03/14/2021 